\title{
Three-Dimensional Chlorophyll Concentrations in a High Biomass Blue Grama Canopy
}

\section{J. TUCKER AND M. W. GARRATT}

Highlight: The three-dimensional chlorophyll variation in $50-\mathrm{cm}$ high blue grama canopy was investigated. Statistical analysis revealed significant differences in the vertical dimension and a quadratic relationship between chlorophyll density and height. Maximum canopy chlorophyll concentrations occurred in the $12.5-25.0 \mathrm{~cm}$ vertical region with the lowest concentrations occurring in the $0.0-12.5 \mathrm{~cm}$ and 37.5-50.0 vertical region.

The chlorophyll distribution in a grassland canopy directly implies information concerning the photosynthetic activity of that canopy. Little variation in the north-south and east-west concentrations would be expected for a homogeneous canopy. Vertical chlorophyll concentrations in a high biomass grass canopy are related to light penetration and the vertical biomass distribution and would be expected to vary to a large degree. Pursuant to this, a $1-\mathrm{m}^{2}$ plot of blue grama (Bouteloua gracilis) was selected to study the variation of chlorophyll density within the width, length, and height of the canopy.

\section{Methods}

The square meter plot was divided into 64 cells $\left(4^{3}=64\right)$, having the dimensions of $25 \times 25 \times 12.5 \mathrm{~cm}$ for width, length, and height, respectively. The width and length dimensions corresponded to the east-west and north-south orientation of the plot sampled. The blue grama canopy studied was located in the Environmental Stress Area of the International Biological Program's Grassland Biome Pawnee Site near Nunn, Colorado. The particular location selected for study was in an irrigated and nitrogen-fertilized area and had a biomass of 530 $\mathrm{g} / \mathrm{m}^{2}$. The time of sampling was early August in 1972.

A three-dimensional grid was set up with twine to delineate the compartmentalization of the canopy. Clipping was then initiated, beginning from the uppermost layer and proceeding downward. Clipped vegetation was immediately placed into a plastic bag, sealed, and stored on dry ice in a large styrofoam ice chest. Care was taken to prevent exposure to sunlight or warm air. At the conclusion of the clipping, the clipped vegetation was taken into the IBP laboratory where a representative aliquot was taken from each of the 64 samples.

Two chlorophyll determinations per sample aliquot were made and were expressed as milligrams of chlorophyll per gram dry weight (Horwitz, 1970). The means of each pair of determinations were the data employed in the statistical analysis. The experiment was analyzed as a three-way factorial design with the vertical, north-south, and east-west dimensions as the three factors. Orthogonal polynomials were employed to break the significant sum of squares, the vertical dimension, into its linear, quadratic, and cubic components (Cochran and Cox, 1957) (Table 1).

Authors are graduate research assistants, US/IBP Grassland Biome, Natural Resource Ecology Laboratory, Colorado State University, Fort Collins.

This paper reports on work supported in part by the National Science Foundation Grants GB-31862X and GB-41233X to the Grassland Biome, U.S. International Biological Program, for "Analysis of Structure, Function, and Utilization of Grassland Ecosystems." The authors acknowledge Cleon Ross for his assistance with the chlorophyll determinations and Robert Oliver and Joseph Berry for their field assistance.

Manuscript received January 20, 1975.
Table 1. Analysis of variance of the chlorophyll variation in the blue grama canopy.

\begin{tabular}{lrrrrr}
\hline \multicolumn{1}{c}{ Source } & $\begin{array}{c}\text { Sum of } \\
\text { squares }\end{array}$ & df & M.S. & $F$-value & $\begin{array}{c}\text { Prob. } \\
\text { greater } F\end{array}$ \\
\hline Total & 15.942 & 63 & - & - & - \\
East-west (E-W) & 0.183 & 3 & 0.061 & 0.679 & 0.573 \\
North-south (N-S) & 0.557 & 3 & 0.186 & 2.065 & 0.128 \\
Vertical & 10.569 & 3 & 3.523 & 39.226 & 0.000 \\
$\quad$ Linear & 2.926 & 1 & 2.926 & 32.523 & 0.000 \\
$\quad$ Quadratic & 7.314 & 1 & 7.314 & 81.306 & 0.000 \\
$\quad$ Cubic & 0.329 & 1 & 0.329 & 3.653 & 0.067 \\
E-W X N-S & 0.443 & 9 & 0.049 & 0.548 & 0.826 \\
E-W X vertical & 1.058 & 9 & 0.118 & 1.307 & 0.279 \\
N-S X vertical & 0.702 & 9 & 0.078 & 0.867 & 0.565 \\
Error & 2.429 & 27 & 0.090 & - & - \\
\hline
\end{tabular}

\section{Results}

The results show the marked vertical chlorophyll concentration differences that exist in the canopy. The uppermost layer shows the lowest concentration of chlorophyll per unit weight of tissue $(0.728 \mathrm{mg} / \mathrm{g})$ because the blue grama seedheads in this vertical zone $(37.5-50 \mathrm{~cm})$ are not photosynthetically active. Lower canopy layers show increased chlorophyll concentrations which rise to maximum of $1.851 \mathrm{mg} / \mathrm{g}$ in the $12.5-25.0 \mathrm{~cm}$ zone. The chlorophyll concentration then begins to decrease with lower canopy depths (i.e., 0.0 to $12.5 \mathrm{~cm}$ ). A Tukey's test revealed no significant difference at the 0.05 level between the mean chlorophyll concentrations in the 0.0 to $12.5-\mathrm{cm}$ zone and the 25.0 to $37.5-\mathrm{cm}$ zone. All other differences in the mean chlorophyll concentrations were significant at the 0.05 level.

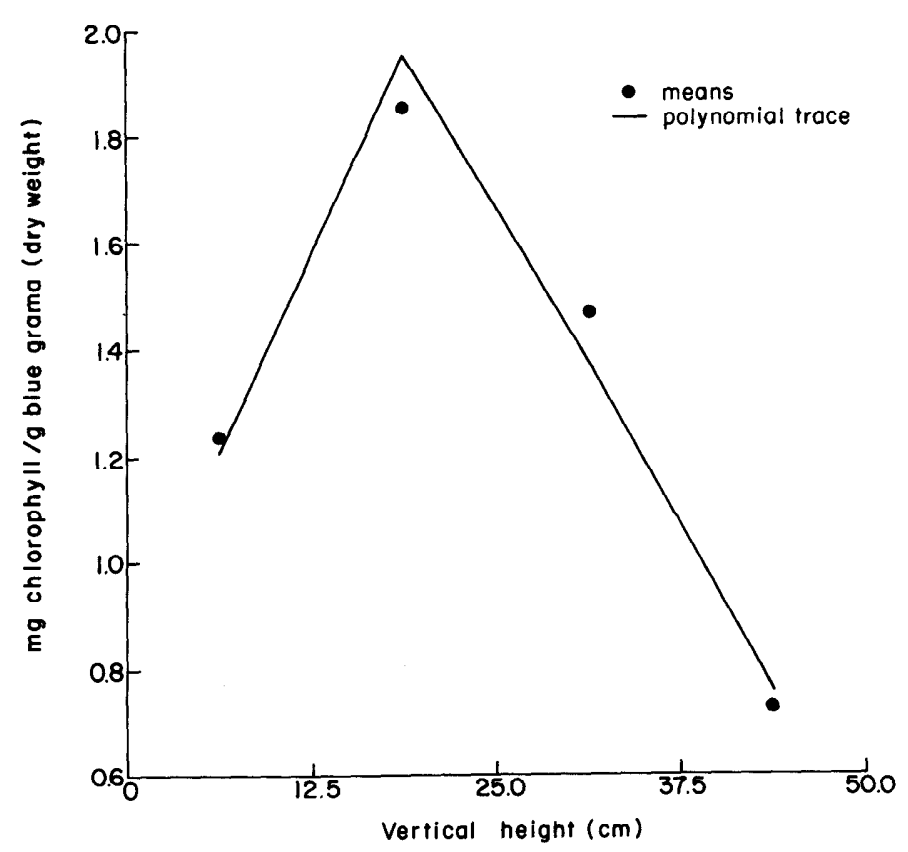

Fig. 1. Estimated means and polynomial of chlorophyll of blue grama in the vertical dimension. 
The relationship between chlorophyll concentration and vertical height can be approximated by a quadratic function (Fig. 1) of the form:

$$
\hat{\mathrm{Y}}=1.321+0.096 \mathrm{X}-0.338 \mathrm{X}^{2}
$$

where $\hat{\mathbf{Y}}$ is the estimated chlorophyll concentration and $\mathbf{X}$ is the height within the canopy.

In addition, the 0.0 to $12.5-\mathrm{cm}$ zone reflects the diminished light penetration but apparently compensates for this in terms of total chlorophyll by having proportionally higher biomass near the base. The results of this experiment support the contention that little variation occurred in the north-south and east-west directions, while significant variations occurred in the vertical dimension. The analysis implies that maximum chlorophyll concentration and hence photosynthetic activity occur in the 0.0 to $37.5-\mathrm{cm}$ region of the high biomass blue grama canopy studied.

\section{Literature Cited}

Cochran, W. G., and G. M. Cox. 1957. Experimental design. John Wiley and Sons, Inc., New York. p. 550-553.

Horwitz, W. (Ed.) 1970. Official methods of analysis (11th Ed.) Association of Analy tical Chemists, Washingtun, D.C. p. 53-55. 